\title{
Curing kinetics, mechanism and chemorheological behavior of methanol etherified amino/novolac epoxy systems
}

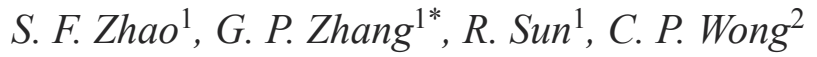 \\ ${ }^{1}$ Shenzhen Institutes of Advanced Technology, Chinese Academy of Sciences, Shenzhen, China \\ ${ }^{2}$ Department of Electronic Engineering, Faculty of Engineering, The Chinese University of Hong Kong, Hong Kong, China
}

Received 4 August 2013; accepted in revised form 29 September 2013

\begin{abstract}
The curing kinetics and mechanism of epoxy novolac resin (DEN) and modified epoxy novolac resin (MDEN) with methanol etherified amino resin were studied by means of differential scanning calorimetry (DSC), Fourier transforminfrared (FT-IR) spectroscopy and chemorheological analysis. Their kinetics parameters and models of the curing were examined utilizing isoconversional methods, Flynn-Wall-Ozawa and Friedman methods. For the DEN mixture, its average activation energy $\left(E_{a}\right)$ was $71.05 \mathrm{~kJ} / \mathrm{mol}$ and the autocatalytic model was established to describe the curing reaction. The MDEN mixture exhibited three dominant curing processes, termed as reaction 1, reaction 2 and reaction 3; and their $E_{a}$ were $70.05,106.55$ and $101.91 \mathrm{~kJ} / \mathrm{mol}$, respectively. Besides, $E_{a}$ of reaction 1 was similar to that of DEN mixture, while $E_{a}$ of reactions 2 and 3 corresponded to that of the etherification reaction between hydroxyl and epoxide group. Moreover, these three dominant reactions were $\mathrm{n}^{\text {th }}$ order in nature. Furthermore, their curing mechanisms were proposed from the results of DSC and FTIR. The chemorheological behavior was also investigated to obtain better plastics products via optimizing the processing schedules.
\end{abstract}

Keywords: rheology, autocatalytic kinetic model, curing mechanism, activation energy

\section{Introduction}

Epoxy resins have been widely applied in many areas such as aerospace and electronics industries in the form of surface coatings, structural adhesives, advanced composites and packaging materials due to their well-balanced properties. For example, epoxy resins possess excellent thermal stability, moisture resistance, chemical stability, superior electrical and mechanical properties and good adhesion to many substrates [1-3]. As well as known properties, such as, the superior mechanical and chemical properties of epoxy polymers are profited from the complicated curing processes, in which a low molecular weight oligomer is transformed into an infinite molecular weight polymer forming a three-dimensional network structure. Therefore, elucidation of the reaction mechanism of epoxy curing still attracts great interest for both fundamental and applied chemistry areas. Meanwhile, in the curing reaction of epoxy resins, amino resins are widely used as hardeners but the curing mechanism is still not completely revealed [4-6]. Yong Lv et al. [7] studied the curing kinetics of a diglycidyl ether of bisphenol A with a methanol etherified amino resin, but they did not discuss the origin of proton, which is important to methanol etherified amino resin. Besides, the curing process is related to the rheological behavior. The viscosity of curing system varies not only with temperature and flow conditions but also with reaction time. Therefore, in order to optimize the properties of the cured product, it is important to understand the relationship between the curing kinetics and rheological behavior of the entire epoxy system.

\footnotetext{
${ }^{*}$ Corresponding author, e-mail: gp.zhang@siat.ac.cn

(C) BME-PT
} 
Many efforts have been done to determine the appropriate models to describe the curing kinetics distinctly [8-12]. Because of the complex nature of thermosetting reactions, phenomenological models are the most popular for these systems. The simplest models are those based on $n^{\text {th }}$ order kinetics. Another widely used model is the autocatalytic expression. Regarding rheological behavior, an advance was made from the correlation between viscosity and temperature that include kinetics and/or structure information $[13,14]$. However, there are few studies to investigate the kinetic model from chemorheological behavior.

In our previous work, novolac epoxy resin of DEN 431 (abbreviated as DEN) was modified by phydroxybenzoic acid (PHBA). The modified novolac epoxy resin (MDEN) was cured with amino resin to prepare cured composites with superior thermal, mechanical and dielectric properties [15]. In this work, the curing kinetics, curing mechanism and chemorheological behavior of DEN/amino resin and MDEN/amino resin systems were further investigated to discuss their differences. The curing kinetics of the studied systems was examined by dynamic differential scanning calorimetry (DSC) at different heating rates, and the curing mechanism was proposed by the aid of the results of DSC and Fourier transform-infrared (FT-IR) spectra. Simultaneously, the chemorheological behavior was further investigated to optimize the process schedule.

\section{Experimental}

\subsection{Materials}

Novolac epoxy resin of DEN 431 with epoxy equivalent weight of 177-200 g/mol (Dow Chemical Company, Russellville, Arkansas, USA), methyl etherified amino resin of Cymel 303 (HMMM) (Cytec Industry, Penfield, NY, USA) and 2-ethyl-4-methylimidazole (EMI-24) (Shanghai Chemical Reagent Factory, Shanghai, China) were used as received without further purifications. Modified DEN (MDEN) was prepared according to our previous study [15]. These chemical structures were presented in Figure 1.

\subsection{Characterization}

The FT-IR spectra were recorded on a Bruker Vertex 70 spectrometer (Bruker Optik GmbH, Ettlingen, Germany) in the range of $4000-400 \mathrm{~cm}^{-1}$.
The curing kinetics analysis was conducted by a TA Q20-1173 DSC thermal system (TA instruments, New Castle, USA) with heating rates of 2.5, 5, 10, and $15^{\circ} \mathrm{C} / \mathrm{min}$, respectively, and ranging from 50 to $300^{\circ} \mathrm{C}$. Nitrogen gas was purged at a flow rate of about $50 \mathrm{~mL} / \mathrm{min}$.

The chemorheological behavior was measured using an Anton Paar MCR302 rheometer (Anton Paar $\mathrm{GmbH}$, Graz, Austria) with a heating rate of $2.5^{\circ} \mathrm{C} / \mathrm{min}$ and ranging from 40 to $280^{\circ} \mathrm{C}$.

\subsection{Theoretical calculations}

The heat flow measured in DSC is proportional to both the overall heat release and the curing rate, as shown by Equation (1) [16]:

$$
\frac{\mathrm{d} Q}{\mathrm{~d} t}=Q_{\mathrm{thr}} \frac{\mathrm{d} a}{\mathrm{~d} t}=Q_{\mathrm{thr}} k(T) f(a)
$$

where $\mathrm{d} Q / \mathrm{d} t$ is the heat flow, $Q_{\text {thr }}$ is the total heat released when an uncured material is brought to complete cure, $\mathrm{d} a / \mathrm{d} t$ is the curing rate, $a$ is the extent of reaction, $k(T)$ is the rate constant, $T$ is the temperature, and $f(a)$ is the reaction model. For epoxy curing, $f(a)$ is usually taken in the form of $(1-a)^{\mathrm{n}}\left(n^{\text {th }}\right.$ order reaction) or of $a^{\mathrm{m}}(1-a)^{\mathrm{n}}$ (autocatalytic reaction). The explicit temperature dependence of the rate constant is introduced by replacing $k(T)$ with the Arrhenius equation (Equation (2)):

$$
\frac{\mathrm{d} a}{\mathrm{~d} t}=A \exp \left(-\frac{E}{R T}\right) f(a)
$$

where $A$ is the pre-exponential factor, $E$ is the activation energy, and $R$ is the gas constant. When a sample is heated at a constant rate, the explicit temporal dependence in Equation (2) is eliminated through the transformation shown by Equation (3):

$$
\frac{\mathrm{d} a}{\mathrm{~d} T}=\frac{A}{\beta} \exp \left(-\frac{E}{R T}\right) f(a)
$$

where $\beta=\mathrm{d} T / \mathrm{d} t$ is the heating rate. Kinetics analysis of a nonisothermal resin-cured system can be performed by the multiple $\beta$. Two different isoconversional methods employed in this study were as follows, and the advantage of the two kinetics methods is that they do not assume a particular form of the reaction model.

\subsubsection{Flynn-Wall-Ozama method}

The isoconversional integral method was also proposed independently by Flynn, Wall and Ozawa 
using Doyle's approximation of the temperature integral $[17,18]$. This method is based on Equations (4) and (5):

$\ln \beta=\ln \left(A \frac{E_{a}}{R}\right)-\ln g(a)-5.331-1.052\left(\frac{E_{a}}{R T}\right)$

$g(a)=\int_{0}^{a} \frac{\mathrm{d} a}{f(a)}$

where $g(a)$ is the integral conversion function.

This method has been used in present computations of the activation energy at different values of conversion. Thus, for a constant $a$, the plot of $(\ln \beta)$ vs. $(1 / T)$ obtained from DSC thermograms using various heating rates, should render a straight line where the slope allows the determination of the apparent activation energy. The experimentally evaluated values of the activation energy were used to determine the appropriate kinetic model which best described the conversion function of the process studied.

\subsubsection{Friedman method}

The Friedman method is also used to determine a kinetic model of the curing process [19]. The method is based on Equation (6):

$\ln \frac{\mathrm{d} a}{\mathrm{~d} t}=\ln \beta \frac{\mathrm{d} a}{\mathrm{~d} T}=\ln [A f(a)]-\frac{E_{a}}{R T}$

In case of the $\mathrm{n}^{\text {th }}$-order reaction, Equation (6) was transformed into Equation (7):<smiles>COCN(COC)c1nc(N(COC)COC)nc(N(COC)COC)n1</smiles>

HMMM<smiles>CCc1nc(C)c[nH]1</smiles>

EMI-24

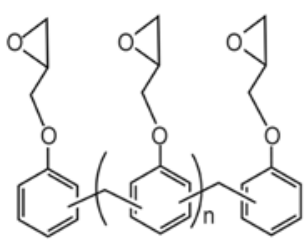

DEN

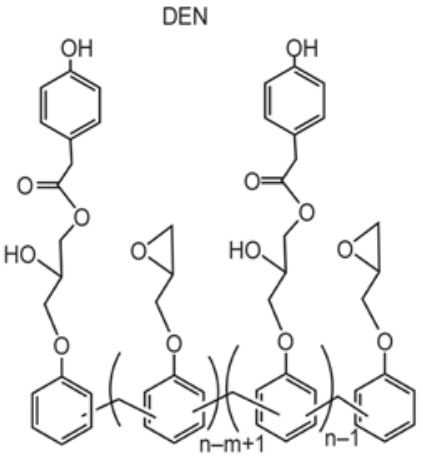

MDEN
Figure 1. Chemical structures of HMMM, EMI-24, DEN and MDEN $\ln [A f(a)]=\ln \left[\frac{\mathrm{d} a}{\mathrm{~d} t}\right]+\frac{E_{a}}{R T}=\ln A+n \ln (1-a)$

The value of $\ln [A f(a)]$ can be obtained from the known values of $\ln [\mathrm{da} / \mathrm{dt}]$ and $E_{a} / R T$. Therefore, the plot of $\ln [A f(a)]$ and $\ln (1-a)$ yields a straight line where the slope corresponds to the reaction order $(n)$. The intercept is the natural logarithm of the frequency factor if the reaction mechanism is $\mathrm{n}^{\text {th }}$-order kinetics. Otherwise, for autocatalytic process, the Friedman plot would reveal a maximum of $\ln (1-a)$ approximately around -0.51 to -0.22 which is equivalent to degree of curing $(a)$ of about 0.2-0.4. This is due to the autocatalytic nature that shows the maximum reaction rate to be at $20-40 \%$ conversion.

\section{Results and discussion}

\subsection{Reaction activities of DEN and MDEN}

The reaction activities of DEN and MDEN were investigated by non-isothermal DSC with HMMM and EMI-24 as curing agent and accelerator, respectively. It can be seen from Figure 2 that there was no obvious exothermic peak appearing in the mixture of DEN/HMMM, which indicated that the reaction activity of the system was pretty low without cross linking reaction happening. Besides, in the mixture of DEN/HMMM, one sharp endothermic peak at about $155^{\circ} \mathrm{C}$ can be ascribed to the evaporation of residual solvent in DEN or HMMM, such as an ether. In contrast, there was a broad exothermic peak existing in MDEN/HMMM system between 85 and $275^{\circ} \mathrm{C}$, which implied that the reaction activity of MDEN/HMMM system was higher than that of DEN/HMMM system. Interestingly, adding EMI24 into the DEN/HMMM system, one obvious exothermic peak at about $150^{\circ} \mathrm{C}$ with much narrower

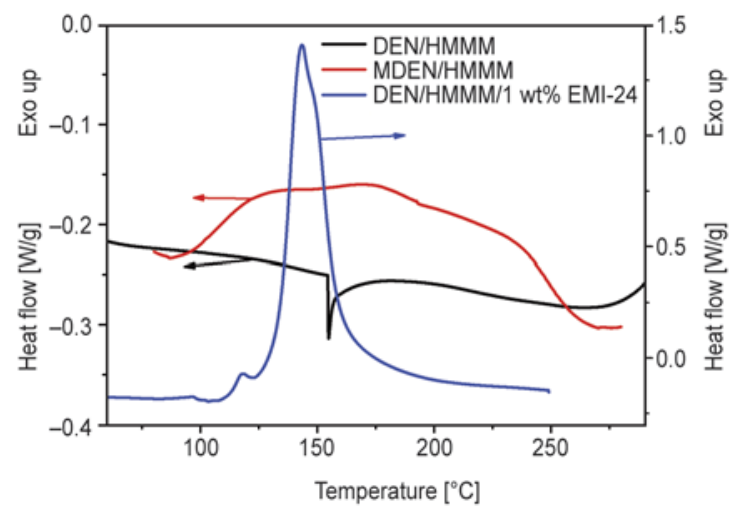

Figure 2. DSC curves based on the systems of DEN mixture and MDEN mixture at $10^{\circ} \mathrm{C} / \mathrm{min}$ 
temperature zone was present in the DSC curve. The higher reaction activity of MDEN was resulted from the phenol hydroxyl which could offer the acidic environment.

\subsection{Non-isothermal reactions of DEN/HMMM/EMI-24 and MDEN/HMMM}

The non-isothermal DSC curves for the epoxy resin system examined in the study at different heating rates ranging from 2.5 to $15^{\circ} \mathrm{C} / \mathrm{min}$ were shown in Figures $3 \mathrm{a}, 3 \mathrm{~b}$ and $3 \mathrm{c}$. It can be found that two exothermic peaks were observed in the curing process of DEN/HMMM/EMI-24 as shown in Figure 3a. This phenomenon was conflicted with the curing reaction of common epoxy-amine system. For example, according to previous work of Sbirrazzuoli et al. [20], only a single exothermic peak was found in the stoichichiometric epoxy-amine system and the epoxy system with excess of amine. Besides, the onset, peak, and final cure temperature of exothermic peaks shifted to higher temperature area with increasing heating rates. This result can be ascribed that lower heating rates offered longer time for the reaction of chemical groups. However, at higher heating rates, there was not enough time for curing and therefore the DSC curves shifted to a higher temperature to compensate for the reduced time.
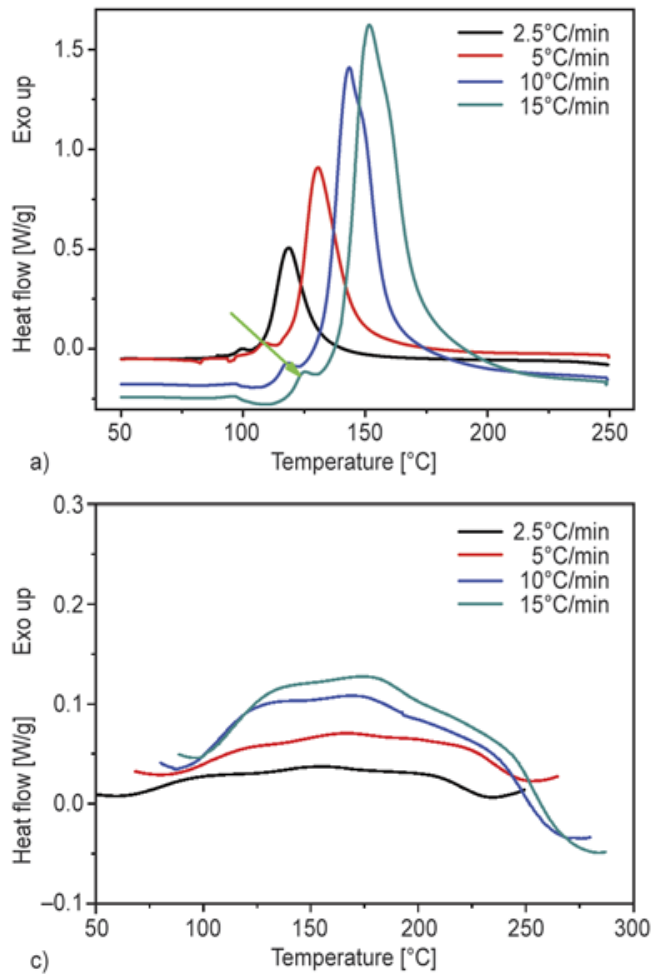

In order to verify the origin of the low temperature peaks identified with arrow, the curing of DEN/ EMI-24 systems was also traced at the same heating rates as shown in Figure 3b. It could be seen that the peak temperatures of DEN/EMI-24 were the same as these of DEN/HMMM/EMI-24 at lower temperature area at respective heating rates. Generally, imidazole with low content was used to catalyze and study the etherification. Heise and Martin [21] found that the $-\mathrm{OH}$-adduct reaction occurred only for 1-unsubstituted imidazoleles (such as EMI24) with a shoulder on the main exothermic peak at low EMI-24 concentrations. However, for the 1substituted imidazoles, the $\mathrm{OH}$-adduct reaction did not occur; only the $\mathrm{O}^{-}$-adduct reaction occurred through 3-N with the epoxide ring without similar shoulder. Regrettably, Heise and Martin [21] did not explain why $\mathrm{OH}$-adduct reaction could form a shoulder and $\mathrm{O}^{-}$adduct reaction could not form a shoulder. These observations were consistent with the results of Ooi et al. [4]. The curing mechanism of DGEBA/EMI-24 was studied by Chen and Liu [22] and they revealed that the whole curing reaction was divided into two independent stages. $\mathrm{OH}-$ adduct reaction and $\mathrm{O}^{-}$-adduct reaction were responsible for the first exothermic peak and etherification reaction led to the second exothermic peak.
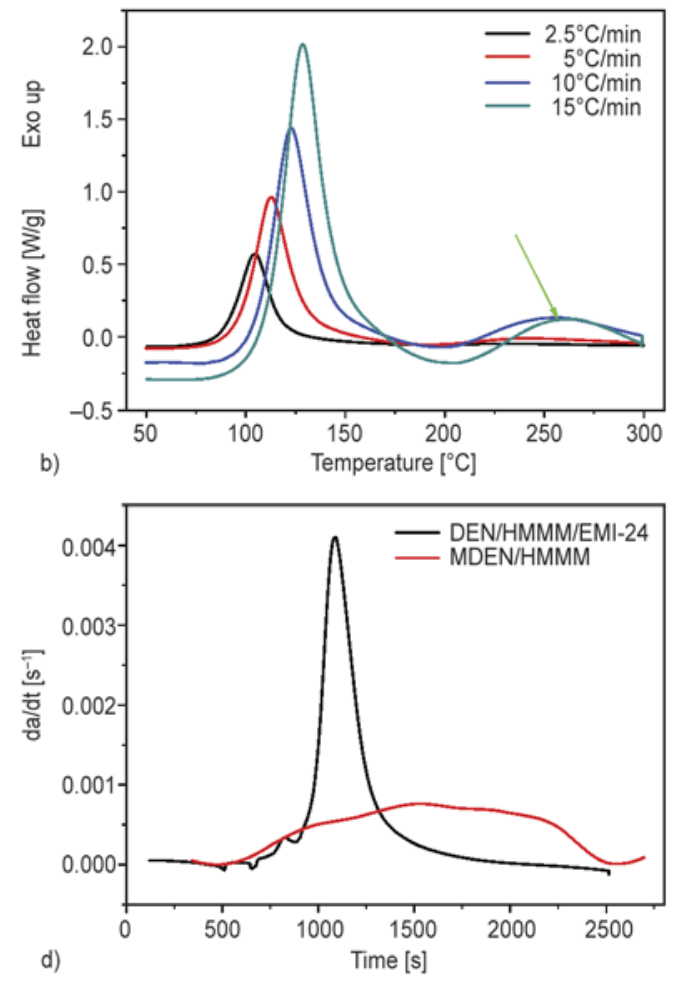

Figure 3. Non-isothermal DSC curing behavior of (a) DEN/HMMM/EMI-24, (b) DEN/EMI-24, (c) MDEN/HMMM and (d) their curing reaction rates at the heating rate of $5^{\circ} \mathrm{C} / \mathrm{min}$ 
However, the common results of previous work were that the first exothermic peak got smaller and smoother with the decrease of the concentrations of 1-unsubstituted imidazoles. In the previous study reported by Ooi et al. [4], it was difficult to observe that the lower temperature peak or shoulder was present at $1 \mathrm{wt} \%$ of $2-\mathrm{PhI}$. Therefore, it was understandable that no lower temperature peak or shoulder occurred in the DEN/EMI-24 system and the corresponding curing mechanism has now been generally accepted without debate. From Figure 3a and $3 \mathrm{~b}$, it could be concluded that the first exothermic peak was attributed to the reaction between DEN and EMI-24, and the main peak was due to the reaction between DEN and HMMM.

Figure $3 \mathrm{c}$ represented the dynamic thermograms of MDEN/HMMM system. Each of the DSC runs showed a broad exothermic peak with shoulders, which likely suggested that the non-isothermal reaction can be considered as a combination of different kinetics process from a statistical viewpoint [23]. Compared to DEN/HMMM/EMI-24, the value of heat flow was relatively low and stable during the whole curing process, which indicated the curing reaction was relatively mild. It would need much more time to complete the curing and decrease the internal stress during curing. This curing reaction behavior was further verified as shown in Figure $3 \mathrm{~d}$. For curing of DEN/HMMM/EMI-24 at the heating rate of $5^{\circ} \mathrm{C} / \mathrm{min}$, the maximum curing rate reached $0.004 \mathrm{~s}^{-1}$, which was fivefold than that of MDEN/HMMMM (about $0.0008 \mathrm{~s}^{-1}$ ). On the other hand, it needed about $2000 \mathrm{~s}$ to complete the curing reaction for the system of MDEN/HMMM at the above condition.

\subsection{Kinetic model}

From the aforementioned DSC results, it could be seen that MDEN had wider temperature range to complete the curing reaction, which indicated that their curing mechanisms were also different. In order to reveal their differences, the kinetic model was examined utilizing isoconversional methods. It was known that the reaction activation energy $\left(E_{a}\right)$ represented the potential barrier and the evolution of the curing reaction [8]. As shown previously for epoxy curing, model-free iso-conversional kinetics analysis could allow one to yield reliable kinetics parameters as well as to accomplish agreement with isothermal data. Without assuming a particular form for the reaction model, these methods allow for evaluating $E_{a}$ as a function of conversion (a). This $E_{a^{-}} a$ correlation usually corresponded to change of reaction mechanisms; it may reflect relative contributions of parallel reaction channels to overall reaction kinetics $[24,25]$. In this work, Flynn-WallOzawa method was employed to analyze the mechanism of the non-isothermal reaction. Based on Equation (4) through linear fitting of $\ln (\beta)$ versus $1 / T$, the values of $E_{a}$ were obtained for a particular $a$.

The variation of $E_{a}$ with the conversion $(a)$ and that of conversion with temperature were shown in Figure 4 . It could be observed that the values of $E_{a}$ varied with the increase of $a$ and exhibited a significantly changing characteristic during the curing reaction. For DEN/HMMM/EMI-24, the curing process was characterized by a decrease in $E_{a}$ from $\approx 80$ to $\approx 50 \mathrm{~kJ} / \mathrm{mol}$. The decrease of $E_{a}$ implied that the rate determining step of curing changed to a process with smaller $E_{a}$ [26]. The curing rate was generally controlled by the rate of chemical reaction and the diffusion of reactants. When the molecular motion was hindered and molecules only experienced a series of diffusion jumps to engage in a chemical reaction, the diffusion became a rate determining factor. Therefore, the decrease in $E_{a}$ was attributed to diffusion control [20]. An interpretation of this behavior of $E_{a}$ variation with conversion was an apparent decrease in molecular mobility and the polymer gels or due to a kinetic compensation effect has been reported [23]. To eliminate these effects, the mean value of the $E_{a}$ at the conversion of curing in ranges of $0.1-0.5$, was found to be $71.05 \mathrm{~kJ} / \mathrm{mol}$, which was quite typical for epoxy/ amine copolymerization [25]. However, for the sys-

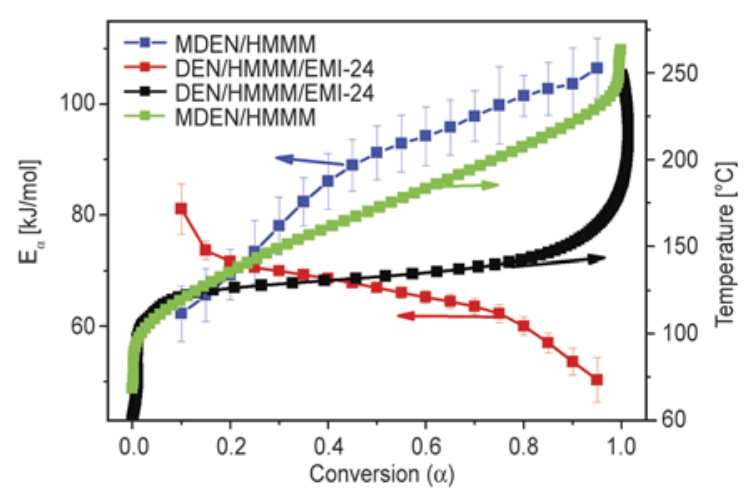

Figure 4. Variation of $E_{a}$ on the conversion and the dependence of the conversion on temperature at the heating rate of $5^{\circ} \mathrm{C} / \mathrm{min}$ for DEN/HMMM/EMI-24 and MDEN/HMMM systems 
tem of MDEN/HMMM, the $E_{a}$ of the curing process increased to $\approx 106 \mathrm{~kJ} / \mathrm{mol}$ from the value of $\approx 61 \mathrm{~kJ} / \mathrm{mol}$. The increase in $E_{a}$ indicated that chemical reaction was still a rate determining factor. Although, increase of the conversion resulted in the higher glass transition temperature $\left(T_{\mathrm{g}}\right)$ of the polymer products, as soon as the actual experimental temperature rose above the $T_{\mathrm{g}}$, which did not result in the appearance of glass transition effect [27]. In MDEN/HMMM system of Figure 3d, the curing rate was so low that the curing did not increase the $T_{\mathrm{g}}$ obviously, and then the influence of chemical reaction on $E_{a}$ outweighed that of the diffusion, which resulted in the increase of $E_{a}$. Besides, for MDEN/ HMMM system, the mean value of $E_{a}$ can be calculated as mentioned above method as $77.44 \mathrm{~kJ} / \mathrm{mol}$. From the curve of conversion vs. temperature, it can be seen that the extent of conversion in DEN/ HMMM/EMI-24 was higher than that in MDEN/ HMMM at the same temperature. This was consistent with the difference in the $E_{a}$ and higher $E_{a}$ value would lead to higher barrier [24].

To construct the kinetic model, the kinetics analysis of DSC curves was carried out by separating of the three dominant overlapping exothermic peaks using Gaussian distribution equation and analyzing the distinct characteristic of each exothermic peak. As an example of MDEN/HMMM, the DSC thermogram (solid line) and the calculated data (dashed line) with three resolved peaks were illustrated in Figure $5 \mathrm{a}$, at a heating rate of $5^{\circ} \mathrm{C} / \mathrm{min}[23,28]$. According to Flynn-Wall-Ozawa method, the variation of $E_{a}$ for the three reactions at different conversion was shown in Figure $5 \mathrm{~b}$. It can be seen that the $E_{a}$ values tended to increase with the increase of conversion for reaction 1 and the $E_{a}$ values kept at a more comparative steady state for reactions 2 and 3 . Besides,

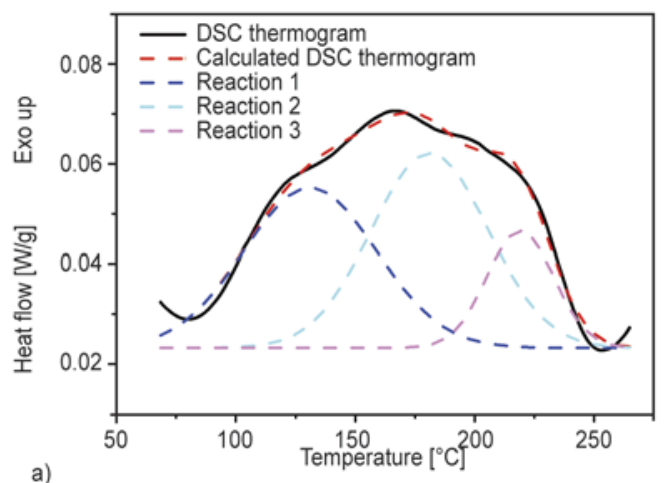

the mean $E_{a}$ value $(70.05 \mathrm{~kJ} / \mathrm{mol})$ for reaction 1 was almost the same as that $(71.05 \mathrm{~kJ} / \mathrm{mol})$ of DEN/ HMMM/EMI-24. This implied that the mechanism of reaction 1 was similar or same as the reaction of DEN/HMMM/EMI-24. By the aid of the catalyst $\left(\mathrm{H}^{+}\right)$, the $-\mathrm{OCH}_{3}$ reacted with epoxide group and hydroxyl group as shown in Figure 9. Meanwhile, the mean $E_{a}$ values for reactions 2 and 3 were 106.55 and $101.91 \mathrm{~kJ} / \mathrm{mol}$, respectively, which were in excellent agreement with those reported for etherification by Cole et al. [29] $(101.4 \mathrm{~kJ} / \mathrm{mol})$ and Sbirrazzuoli et al. [30] (104 kJ/mol). This corresponding etherification was shown in Figure 9. Because the constancy of $E_{a}$ indicated a single limiting process, reaction 2 was attributed to the ringopening reaction of epoxide with phenol hydroxyl, and reaction 3 resulted from the ring-opening reaction of epoxide with hydroxyl activated by neighboring carbonyl group. From the chemical structure of MDEN, it could be seen that etherification may occur intramolecularly, which was influenced somewhat by diffusion.

In our case, the average $E_{a}$ value obtained from Flynn-Wall-Ozawa method was used for the determination of the reaction order of the DEN/HMMM/ EMI-24 and MDEN/HMMM. In general, the mechanisms of thermoset curing were classified into two major kinetic reactions, an $n^{\text {th }}$-order and an autocatalytic reaction. Friedman method was usually employed to construct kinetic model. Figure 6 depicted Friedman plots as an exemplification of DEN/HMMM/EMI-24, the reactions 1, 2 and 3 of MDEN/HMMM at a heating rate of $5^{\circ} \mathrm{C} / \mathrm{min}$. For DEN/HMMM/EMI-24, since $\ln [A f(a)]$ and $\ln (1-a)$ were not linearly related and evidently showed a maximum in the range of the degree of conversion mentioned above. All the results suggested that cur-

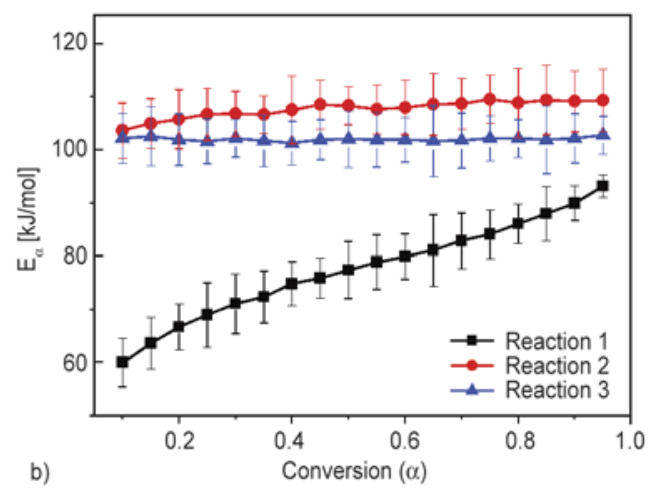

Figure 5. (a) DSC thermograms of MDEN/HMM recorded at $5^{\circ} \mathrm{C} / \mathrm{min}$ and (b) values of the $E_{a}$ of MDEN/HMMM obtained from Flynn-Wall-Ozawa method at different conversion of curing 
ing reaction was autocatalytic in nature. The autocatalytic nature can be explained by the transformation of protons. For reactions 1, 2, and 3, $\ln [A f(a)]$ and $\ln (1-a)$ were perfectly linearly related in the range of the degree of conversion mentioned above, which indicated that all reactions were $\mathrm{n}^{\text {th }}$ order in nature.

For the $\mathrm{n}^{\text {th }}$-order model, the kinetics parameters $\mathrm{n}$ and $A$ could be obtained by the slope of the linear dependence $\ln [A f(a)]$ vs. $\ln (1-a)$, according to the Equation (7). The results of the kinetics parameters for reaction 1, reaction 2 and reaction 3 were listed in Table 1.

For the autocatalytic model, Equation (6) was transformed into Equation (8):

$$
\begin{aligned}
\ln [A f(a)] & =\ln \left[\frac{\mathrm{d} a}{\mathrm{~d} t}\right]+\frac{E_{a}}{R T} \\
& =\ln A+n \ln (1-a)+m \ln (a)
\end{aligned}
$$

Equation (8) can be solved by multiple linear regression, in which the dependent variable was $\ln (\mathrm{d} a / \mathrm{d} t)$, and the independent variables were $\ln (a), \ln (1-a)$ and $1 / T$. The results of the multiple linear regressions analysis for DEN/HMMM/EMI-24 were listed in Table 2. It can be seen that the variations of $A, m$, and $n$ with the heating rate were in the same ranges as those reported by Hardis et al. [13].

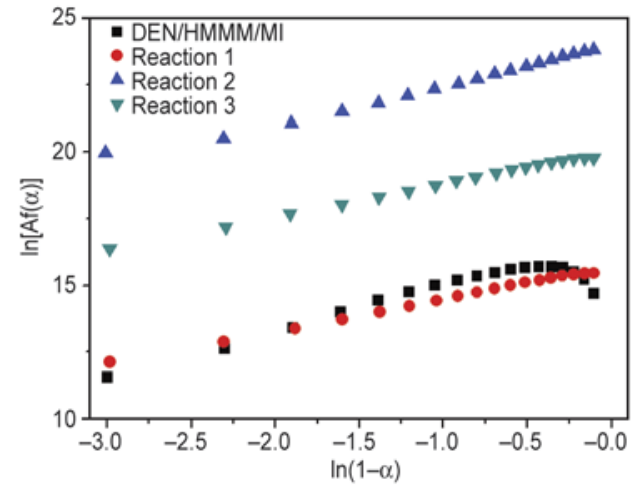

Figure 6. Plots of $\ln [A f(a)]$ vs. $\ln (1-a)$ of $\mathrm{DEN} / \mathrm{HMMM} /$ EMI-24 and MDEN/HMMM based on the $E_{a}$ from Flynn-Wall-Ozawa method at a heating rate of $5^{\circ} \mathrm{C} / \mathrm{min}$

\subsection{Isothermal FTIR analysis}

To elucidate the cross-linking mechanism, FTIR spectroscopy could be employed to track the changes of chemical bonds during the process of curing reaction. The rotation and vibration information was very specific to the chemical bonds, and the peaks in the spectrum corresponded to certain chemical bonds allowing simple identifications. The relative intensity of peaks was also directly proportional to the relative concentration of the components in a sample [31-33]. Isothermal FTIR analysis of the curing of DEN/HMMM/EMI-24 and MDEN/HMMM

\begin{tabular}{|c|c|c|c|c|c|c|}
\hline & $\begin{array}{c}\text { Heating rate } \\
{\left[{ }^{\circ} \mathrm{C} / \mathrm{min}\right]}\end{array}$ & $\begin{array}{c}\text { E/SD } \\
{[\mathrm{kJ} / \mathrm{mol}]}\end{array}$ & $\begin{array}{l}\ln A \\
{\left[\mathbf{s}^{-1}\right]}\end{array}$ & Mean/SD & $\mathbf{n}$ & Mean/SD \\
\hline \multirow[t]{4}{*}{ Reaction 1} & 2.5 & \multirow{4}{*}{$70.05 / 5.85$} & 16.14 & \multirow{4}{*}{$16.25 / 0.26$} & 1.31 & \multirow{4}{*}{$1.24 / 0.05$} \\
\hline & 5 & & 15.96 & & 1.21 & \\
\hline & 10 & & 16.34 & & 1.25 & \\
\hline & 15 & & 16.57 & & 1.20 & \\
\hline \multirow[t]{4}{*}{ Reaction 2} & 2.5 & \multirow{4}{*}{$106.55 / 1.57$} & 23.91 & \multirow{4}{*}{$24.26 / 0.24$} & 1.43 & \multirow{4}{*}{$1.58 / 0.10$} \\
\hline & 5 & & 24.38 & & 1.61 & \\
\hline & 10 & & 24.31 & & 1.64 & \\
\hline & 15 & & 24.45 & & 1.62 & \\
\hline \multirow[t]{4}{*}{ Reaction 3} & 2.5 & \multirow{4}{*}{$101.91 / 0.37$} & 20.10 & \multirow{4}{*}{$20.04 / 0.08$} & 1.28 & \multirow{4}{*}{$1.26 / 0.04$} \\
\hline & 5 & & 20.03 & & 1.23 & \\
\hline & 10 & & 19.94 & & 1.27 & \\
\hline & 15 & & 20.11 & & 1.27 & \\
\hline
\end{tabular}

Table 1. The kinetics parameters evaluated and their standard deviation (SD) for the curing of MDEN/HMMM system

\begin{tabular}{|c|c|c|c|c|c|c|c|}
\hline $\begin{array}{c}\text { Heating rate } \\
{\left[{ }^{\circ} \mathrm{C} / \mathrm{min}\right]}\end{array}$ & $\begin{array}{c}\text { E/SD } \\
{[\mathrm{kJ} / \mathrm{mol}]}\end{array}$ & $\begin{array}{l}\ln A \\
{\left[\mathrm{~s}^{-1}\right]}\end{array}$ & Mean/SD & $\mathbf{n}$ & Mean/SD & $\mathbf{m}$ & Mean/SD \\
\hline 2.5 & \multirow{4}{*}{$71.05 / 4.24$} & 17.90 & \multirow{4}{*}{$17.82 / 0.25$} & 2.13 & \multirow{4}{*}{$2.29 / 0.22$} & 1.18 & \multirow{4}{*}{$1.25 / 0.16$} \\
\hline 5 & & 17.73 & & 2.11 & & 1.13 & \\
\hline 10 & & 18.11 & & 2.59 & & 1.48 & \\
\hline 15 & & 17.52 & & 2.33 & & 1.21 & \\
\hline
\end{tabular}

Table 2. The kinetics parameters evaluated and their standard deviation (SD) for the curing of DEN/HMMM/EMI-24 system 
with definite curing temperatures $\left(160\right.$ and $\left.200^{\circ} \mathrm{C}\right)$ and different curing time $(0,30,45$ and $60 \mathrm{~min})$ were shown in Figures $7 \mathrm{a}, 7 \mathrm{~b}$ and $7 \mathrm{c}$, respectively. To the three samples, the specific peak at $1550 \mathrm{~cm}^{-1}$ attributed to stretching vibration of triazine ring remained unchanged throughout the curing reaction and could be considered as an internal standard. Meanwhile, their corresponding changes of group intensity at various times were also depicted in Figures 7d, 7e and $7 \mathrm{f}$. The peaks at $915 \mathrm{~cm}^{-1}$ were corresponded to the epoxide group and the intensity was observed to decrease over time during the curing reaction. The decrease can be explained by the opening of the epoxide group in the curing process. Besides, it can be found that the characteristics peak at $1385 \mathrm{~cm}^{-1}$
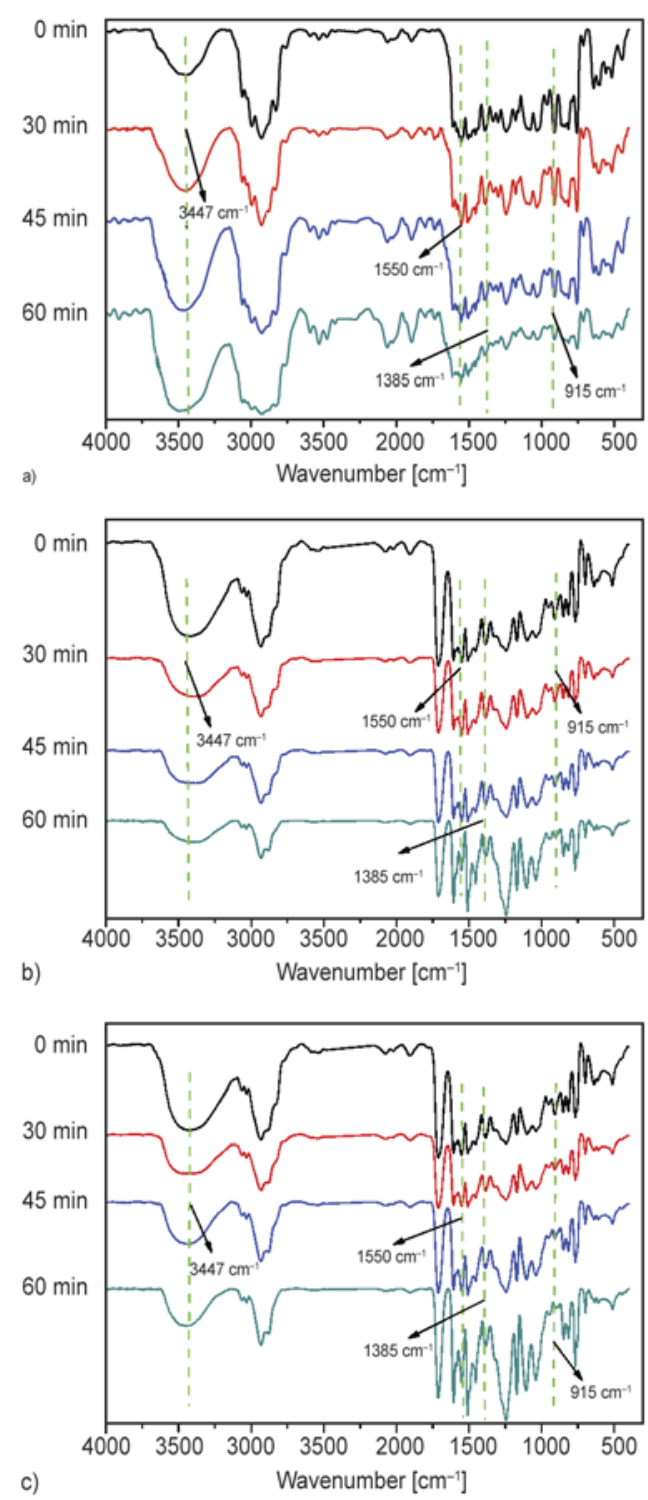

assigned to $-\mathrm{CH}_{3}$ stretching vibration in amino resin also decreased due to its reaction with epoxide group and hydroxyl group. Surprisingly, the peaks at $3447 \mathrm{~cm}^{-1}$ assigned to $-\mathrm{OH}$ stretching vibration increased over time in DEN/HMMM/EMI-24 system, which was due to the higher reaction activity of epoxide than that of hydroxyl, and the produced $-\mathrm{OH}$ was more than the consumed $-\mathrm{OH}$, and these -OH increased the polar of cured polymer [34-37]. The relative high polarity of $-\mathrm{OH}$ resulted in high dielectric constant and water absorption, and the results were consistent with our previous works [15]. While in MDEN/HMMM system, the-OH decreased over time, and the higher curing temperature improved the conversion rate of reactive groups.
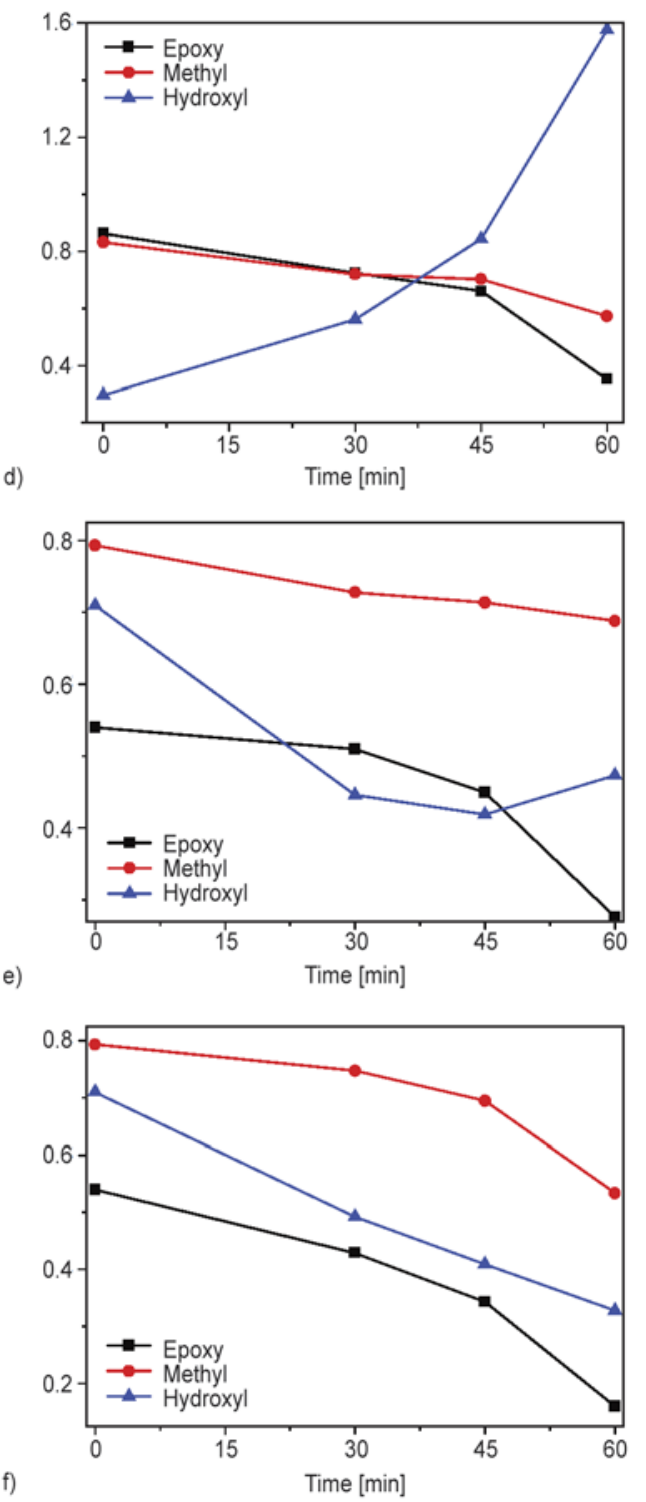

Figure 7. FTIR spectra of three samples at various curing time and their relative intensity change of different reactive groups: DEN/HMMM/EMI-24 at $160^{\circ} \mathrm{C} \quad(\mathrm{a}, \mathrm{d}) ; \mathrm{MDEN} / \mathrm{HMMM}$ at $160^{\circ} \mathrm{C}(\mathrm{b}, \mathrm{e}) ; \mathrm{MDEN} / \mathrm{HMMM}$ at $200^{\circ} \mathrm{C}(\mathrm{c}, \mathrm{f})$ 


\subsection{Mechanism of DEN/HMMM/EMI-24 and MDEN/HMMM}

According to the above results of DSC, FTIR and other relative studies [7, 21, 22, 38], the mechanisms of DEN/HMMM/EMI-24 and MDEN/HMMM were proposed as shown in Figures 8 and 9. From Figure 8 , it could be seen that the transformation of proton can afford the acidic environment to assist the reaction between DEN and HMMM. Besides, due to the higher activity of epoxide, the produced $-\mathrm{OH}$ was more than the consumed $-\mathrm{OH}$. Therefore, these mechanisms could explain that the kinetic model was autocatalytic and the cured DEN resin had higher dielectric constant and water absorption.
Furthermore, from Figure 9, it was observed that phenol hydroxyl can afford the acidic environment, therefore, the phenol hydroxyl and the hydroxyl activated by carboxyl could attack the epoxide and methoxy group, which made the cross linking in intermolecular and intramolecular simultaneously. Compared with DEN/HMMM/EMI-24, the viscosity had less effect on the reaction in MDEN/ HMMM, which could illustrate that the $E_{a}$ increased with conversion.

\subsection{Analysis of chemorheological behavior}

In order to relate the viscosity of the reactive system to the reaction kinetics, the oscillatory shear flow

A

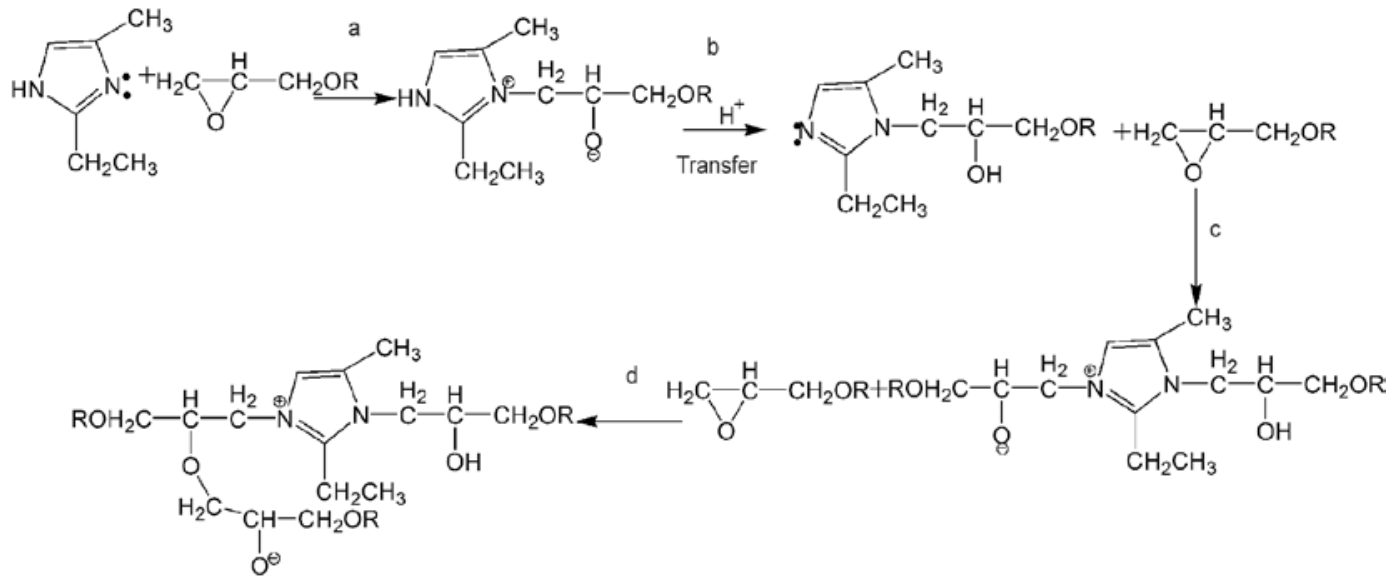

B
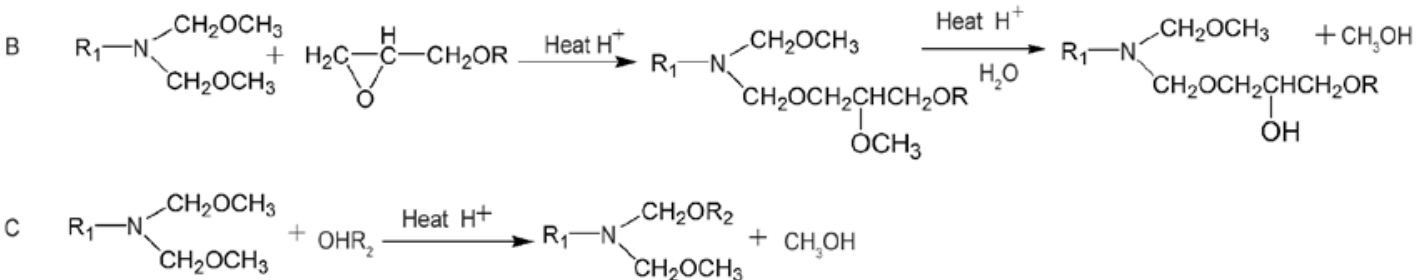

Figure 8. Proposed mechanism for the cure of DEN/HMMM/EMI-24

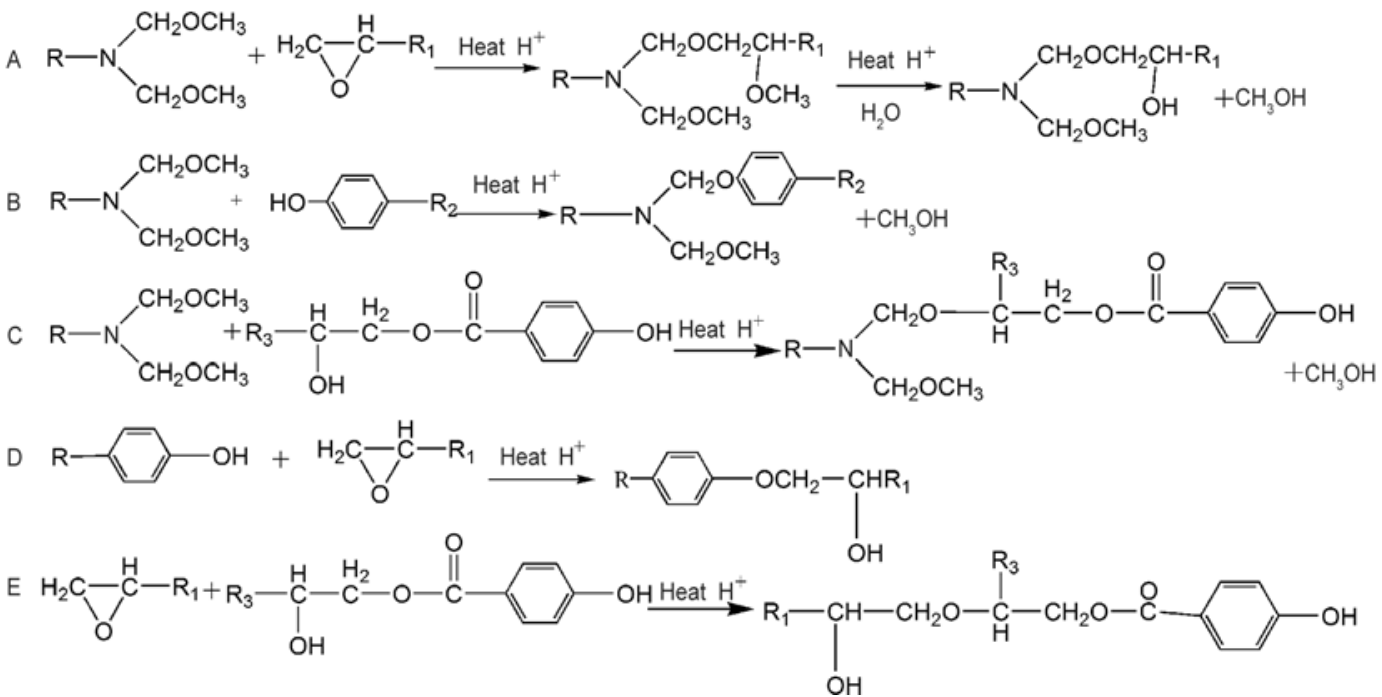

Figure 9. Proposed mechanisms for the cure of MDEN/HMMM 
measurements were performed under non-isothermal condition as the thermocalorimetric measurements. The complex viscosity and the conversion as function of the temperature were plotted in Figure 10. At the beginning, the complex viscosity decreased with temperature, and then a lowest viscosity was obtained at a certain temperature. Thereafter, a very rapid increase of the viscosity was observed with obvious gelation. The following plateau in complex viscosity with temperature appeared ascribing to the dynamic modulus [14]. Besides, for DEN/HMMM/EMI-24, when the conversion $(a)$ was below 0.2 , the low complex viscosity cannot hinder the diffusion of molecule chains. Therefore, the curing was controlled by chemical reaction in this region. Meanwhile, when the conversion $(a)$ was above 0.2 , the viscosity increased rapidly with conversion, the diffusion of molecule chains got difficult, and the curing reaction was controlled by diffusion. Oppositely, for MDEN/HMMM, even the conversion $(a)$ reached to 0.9 , the viscosity was too low to hinder the diffusion of molecular chains. Therefore, the cure reaction was controlled by chemical reaction during almost the whole process. All these results were consistent with $E_{a}$. Moreover, the lowest viscosity can be considered as the watershed in control mechanism of viscosity. Before the watershed, the viscosity was sensitive to temperature and could be controlled by temperature. Therefore, this mode was called physical mechanism of viscous falling. After the watershed, increased temperature could only change the trend in viscosity increase and not decrease the viscosity

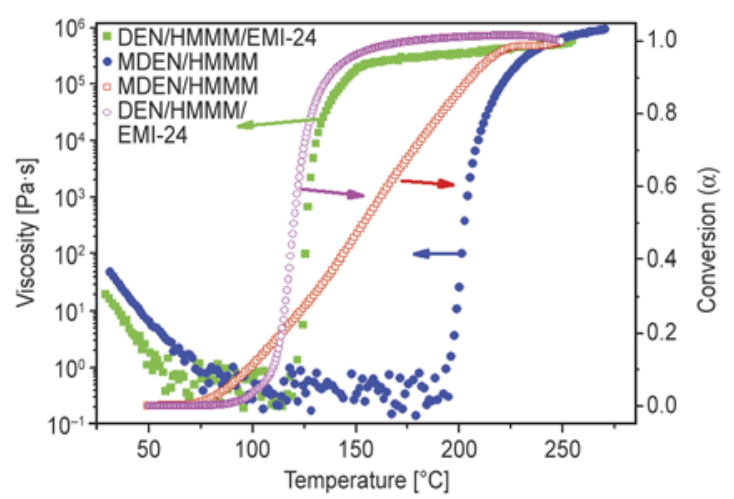

Figure 10. Variation of complex viscosity on temperature and the dependence of the conversion on temperature at the heating rate of $2.5^{\circ} \mathrm{C} / \mathrm{min}$ for DEN/HMMM/EMI-24 and MDEN/HMMM system of reactive system; this mode was called chemical mechanism of viscous increase. These control mechanism could conduct us to obtain better plastics products during resin molding $[39,40]$.

\section{Conclusions}

The curing kinetics of epoxy novolac resin (DEN) and modified epoxy novolac resin (MDEN) with methanol etherified amino resin were studied. The curing reaction of DEN resin mixture was autocatalytic in nature, due to the transformation of protons and its average $E_{a}$ was calculated to be $71.05 \mathrm{~kJ} / \mathrm{mol}$. The curing of MDEN resin mixture was consisted of three dominant reactions (reactions 1, 2 and 3), as evidenced by the presence of two shoulders in the DSC thermograms. Thereinto, the activation energy value of the reaction 1 was similar to that of the DEN resin curing; the activation energy values of reactions 2 and 3 were almost constant (106.55 and $101.91 \mathrm{~kJ} / \mathrm{mol}$, respectively), which were close to those of etherification. The reaction 2 was attributed to the ring-opening reaction of epoxide with phenol hydroxyl, and the reaction 3 was resulted from the ring-opening reaction of epoxide with hydroxyl activated by neighboring carbonyl group. Their possible mechanisms were proposed via the results of FTIR and DSC. At last, chemorheological behavior was also characterized to instruct us preparing better plastics products via controlling viscosity.

\section{Acknowledgements}

This work was financially supported by Guangdong and Shenzhen Innovative Research Team Program (No. 2011D052, KYPT20121228160843692), National Natural Science Foundation of China (Grant No. 21201175) and R\&D Funds for basic Research Program of Shenzhen (Grant No. JCYJ20120615140007998).

\section{References}

[1] Lin C. H., Wang Y. R., Feng Y. R., Wang M. W., Juang T. Y.: An approach of modifying poly(aryl ether ketone) to phenol-containing poly(aryl ether) and its application in preparing high-performance epoxy thermosets. Polymer, 54, 1612-1620 (2013).

DOI: $10.1016 /$ j.polymer.2013.01.034

[2] Li T., Qiu H. J., Liu Y., Zhong X. H., Yu Y. F., Serra A.: Hyperbranched polyester as additives in filled and unfilled epoxy-novolac systems. Polymer, 53, 58645872 (2013). DOI: $10.1016 /$ j.polymer.2012.10.028 
[3] Xu K., Chen M. C., Zhang K., Hu J. W.: Synthesis and characterization of novel epoxy resin bearing naphthyl and limonene moieties, and its cured polymer. Polymer, 45, 1133-1140 (2004).

DOI: $10.1016 /$ j.polymer.2003.12.035

[4] Ooi S. K., Cook W. D., Simon G. P., Such C. H.: DSC studies of the curing mechanisms and kinetics of DGEBA using imidazole curing agents. Polymer, 41, 3639-3649 (2000).

DOI: $10.1016 / \mathrm{S} 0032-3861(99) 00600-X$

[5] Liu W. B., Qiu Q. H., Wang J., Huo Z. C., Sun H.: Curing kinetics and properties of epoxy resin-fluorenyl diamine systems. Polymer, 49, 4399-4405 (2008).

DOI: $10.1016 /$ j.polymer.2008.08.004

[6] Pan G. Y., Du Z. J., Zhang C., Li C. J., Yang X. P., Li H. Q.: Synthesis, characterization, and properties of novel novolac epoxy resin containing naphthalene moiety. Polymer, 48, 3686-3693 (2007).

DOI: $10.1016 /$ j.polymer.2007.04.032

[7] Lv Y., Song C., Long Z., Luo S. Y.: Curing reaction kinetic of a diglycidyl ether of bisphenol A with a methanol etherified amino resin (in Chinese). China Printing and Packaging Study, 3, 44-49 (2011). DOI: $10.3969 /$ j.issn.1674-5752.2011.06.008

[8] Fu Y., Zhong W. H.: Cure kinetics behavior of a functionalized graphitic nanofiber modified epoxy resin. Thermochimica Acta, 516, 58-63 (2011). DOI: $10.1016 /$ j.tca.2011.01.016

[9] Ke L. L., Hu D., Lu Y. B., Feng S., Xie Y. Y., Xu W. J: Copolymerization of maleimide-based benzoxazine with styrene and the curing kinetics of the resultant copolymer. Polymer Degradation and Stability, 97, 132-138 (2012).

DOI: $10.1016 /$ j.polymdegradstab.2011.11.011

[10] Liu L., Ye Z. P.: Effects of modified multi-walled carbon nanotubes on the curing behavior and thermal stability of boron phenolic resin. Polymer Degradation and Stability, 94, 1972-1978 (2009).

DOI: 10.1016/j.polymdegradstab.2009.07.022

[11] Yoo M. J., Kim S. H., Park S. D., Lee W. S., Sun J. W. Choi J. H., Nahm S.: Investigation of curing kinetics of various cycloaliphatic epoxy resins using dynamic thermal analysis. European Polymer Journal, 46, 1158 1162 (2010). DOI: $10.1016 /$ j.eurpolymj.2010.02.001

[12] Han S. O., Drzal L. T.: Curing characteristics of carboxyl functionalized glucose resin and epoxy resin. European Polymer Journal, 39, 1377-1384 (2003).

DOI: 10.1016/S0014-3057(03)00036-3

[13] Hardis R., Jessop J. L. P., Peters F. E., Kessler M. R.: Cure kinetics characterization and monitoring of an epoxy resin using DSC, Raman spectroscopy, and DEA. Composites Part A: Applied Science and Manufacturing, 49, 100-108 (2013). DOI: $10.1016 /$ j.compositesa.2013.01.021
[14] Ivankovic M., Incarnato L., Kenny J. M., Nicolais L.: Curing kinetics and chemorheology of epoxy/anhydride system. Journal of Applied Polymer Science, 90, 3012-3019 (2003). DOI: $10.1002 /$ app. 12976

[15] Zhao S. F., Zhang G. P., Sun R., Wong C. P.: Multifunctionalization of novolac epoxy resin and its influence on dielectric, thermal properties, viscoelastic and aging behavior. Journal of Applied Polymer Science, in press (2013).

[16] Sbirrazzuoli N., Vyazovkin S.: Learning about epoxy cure mechanisms from isoconversional analysis of DSC data. Thermochimica Acta, 388, 289-298 (2002).

DOI: $10.1016 / \mathrm{S} 0040-6031(02) 00053-9$

[17] Kissinger H. E.: Reaction kinetics in differential thermal analysis. Analytical Chemistry, 29, 1702-1706 (1957). DOI: 10.1021/ac60131a045

[18] Ozawa T.: A new method of analyzing thermogravimetric data. Bulletin of the Chemistry Society of Japan, 38, 1881-1886 (1965).

DOI: $10.1246 / \mathrm{bcsj} .38 .1881$

[19] Friedman H. L.: Kinetics of thermal degradation of char-forming plastics from thermogravimetry. Application to a phenolic plastic. Journal of Polymer Science Part C: Polymer Symposia, 6, 183-195 (1965). DOI: $10.1002 /$ polc.5070060121

[20] Sbirrazzuoli N., Vyazovkin S., Mititelu A., Sladic C., Vincent L.: A study of epoxy-amine cure kinetics by combining isoconversional analysis with temperature modulated DSC and dynamic rheometry. Macromolecular Chemistry and Physics, 204, 1815-1821 (2003). DOI: $10.1002 / \mathrm{macp} .200350051$

[21] Heise M. S., Martin G. C.: Curing mechanism and thermal properties of epoxy-imidazole systems. Macromolecules, 22, 99-104 (1989).

DOI: $10.1021 / \mathrm{ma} 00191 \mathrm{a} 020$

[22] Chen P., Liu L. Z.: Curing mechanism, kinetic, reactivities of epoxy resins system cured with 2-ethyl-4methylmidazole (in Chinese). Acta Polymerica Sinica, 6, 641-646 (1994).

[23] Jubsilp C., Punson K., Takeichi T., Rimdusit S.: Curing kinetics of benzoxazine-epoxy copolymer investigated by non-isothermal differential scanning calorimetry. Polymer Degradation and Stability, 95, 918-924 (2010).

DOI: 10.1016/j.polymdegradstab.2010.03.029

[24] Zhang Y. Y., Vyazovkin S.: Comparative cure behavior of DGEBA and DGEBP with 4-nitro-1,2-phenylenediamine. Polymer, 47, 6659-6663 (2006).

DOI: $10.1016 /$ j.polymer.2006.07.058

[25] Zvetkov V. L.: Comparative DSC kinetics of the reaction of DGEBA with aromatic diamines.: I. Non-isothermal kinetic study of the reaction of DGEBA with $\mathrm{m}$ phenylene diamine. Polymer, 42, 6687-6697 (2001). DOI: $10.1016 / \mathrm{S} 0032-3861(01) 00160-4$ 
[26] Lu M. G., Shim M. J., Kim S. W.: Curing reaction and phase change in a liquid crystalline monomer. Macromolecular Chemistry and Physics, 202, 223-230 (2001). DOI: 10.1002/1521-3935(20010101)202:2<223::AIDMACP223>3.0.CO;2-X

[27] Gan L., Sun Z. J., Gu Y. Z., Li M., Zhang Z. G.: Epoxy resin curing reaction studied by dynamic and isothermal model free kinetics. Acta Polymerica Sinica, 8, 1016-1022 (2010). DOI: $10.3724 /$ SP.J.1105.2010.09319

[28] Wan J. T., Li B. G., Fan H., Bu Z. Y., Xu C. J.: Nonisothermal reaction, thermal stability and dynamic mechanical properties of epoxy system with novel nonlinear multifunctional polyamine hardener. Thermochimica Acta, 511, 51-58 (2010).

DOI: $10.1016 / \mathrm{j}$. tca.2010.07.024

[29] Cole K. C., Hechler J. J., Noel D.: A new approach to modeling the cure kinetics of epoxy/amine thermosetting resins. 2. Application to a typical system based on bis[4-(diglycidylamino)phenyl]methane and bis(4aminophenyl) sulfone. Macromolecules, 24, 3098-3110 (1991). DOI: $10.1021 / \mathrm{ma} 00011 \mathrm{a} 012$

[30] Sbirrazzuoli N., Mititelu-Mija A., Vincent L., Alzina C.: Isoconversional kinetic analysis of stoichiometric and off-stoichiometric epoxy-amine cures. Thermochimica Acta, 447, 167-177 (2006). DOI: $10.1016 /$ j.tca.2006.06.005

[31] Li G., Huang Z. B., Li P., Xin C. L., Jia X. L., Wang B. H., He Y. D., Ryu S. K., Yang X. P.: Curing kinetics and mechanisms of polysulfone nanofibrous membranes toughened epoxy/ amine systems using isothermal DSC and NIR. Thermochimica Acta, 497, 27-34 (2010). DOI: $10.1016 /$ j.tca.2009.08.005

[32] Passos S. P., Kimpara E. T., Bottino M. A., Santos G. C. Jr., Rizkalla A. S.: Effect of ceramic shade on the degree of conversion of a dual-cure resin cement analyzed by FTIR. Dental Materials, 29, 317-323 (2013). DOI: $10.1016 /$ j.dental.2012.11.014

[33] Recalde L. B., Recalde D., García-Lopera R., Gómez C. M.: FTIR isothermal cure kinetics and morphology of dicyanate ester resin/polysulfone blends. European Polymer Journal, 41, 2635-2643 (2005). DOI: $10.1016 /$ j.eurpolymj.2005.05.027
[34] Zhao S. F., Cheng L., Guo Y., Zheng Y. Y., Li B. M.: PA6 and Kevlar fiber reinforced isotactic polypropylene: Structure, mechanical properties and crystallization and melting behavior. Materials and Design, 35, 749-753 (2012).

DOI: $10.1016 /$ j.matdes.2011.10.039

[35] Zhao S. F., Qiu S. C., Zheng Y. Y., Cheng L., Guo Y.: Synthesis and characterization of kaolin with polystyrene via in-situ polymerization and their application on polypropylene. Materials and Design, 32, 957-963 (2011).

DOI: $10.1016 /$ j.matdes.2010.07.020

[36] Bortolato S. A., Thomas K. E., McDonough K., Gurney R. W., Martino D. M.: Evaluation of photo-induced crosslinking of thymine polymers using FT-IR spectroscopy and chemometric analysis. Polymer, 53, 5285-5294 (2012).

DOI: $10.1016 /$ j.polymer.2012.09.007

[37] Xiong X. H., Chen P., Ren R., Lu F., Yu Q.: Cure mechanism and thermal properties of the phthalidecontaining bismaleimide/epoxy system. Thermochimica Acta, 559, 52-58 (2013). DOI: $10.1016 /$ j.tca.2013.02.025

[38] Hong X. Y., Chen Q. D., Chen L., Chen M., Wu R. G., Mao H. Q.: Studies on the energy compensation effect in the hybrid polymerization of hexamethoxymethyl melamine(HMMM)-polyol-acrylate (in Chinese). Chemical Journal of Chinese Universities, 23, 744-747 (2003).

[39] Dai X. Q., Zeng J. C., Xiao J. Y., Jiang D. Z., Yin C. P.: A new method for predicting the viscosity of reactive resin systems (in Chinese). Acta Materiea Compositae Sinica, 27, 78-85 (2010).

[40] Monti M., Puglia D., Natali M., Torre L., Kenny J. M.: Effect of carbon nanofibers on the cure kinetics of unsaturated polyester resin: Thermal and chemorheological modelling. Composites Science and Technology, 71, 1507-1516 (2011).

DOI: $10.1016 /$ j.compscitech.2011.06.010 